\title{
The Importance of Playing for Developing Intelligence in Early Childhood
}

\author{
Nur Hazizah \\ Teacher Education of Early Childhood Education \\ Universitas Negeri Padang \\ Padang, Indonesia \\ azizahmpd7@gmail.com
}

\begin{abstract}
The method used to carry out activities is crucial to achieve optimal results. In an effort to stimulate growth and development of early childhood intelligence, the method chosen should be appropriate to the character of early childhood. One of the characters early childhood was like to play. This article discusses the important of play in the development and early childhood intelligence development. Expected educators and parents have a correct understanding of the importance of play activities for young children, so as to optimize the stimulation of intelligence.
\end{abstract}

Keywords - play, development, intelligence, early childhood

\section{Introduction}

The development of early childhood education programs at this time has begun to get a good place in the hearts of almost every citizen. This is evidenced by the growth of early childhood education growth in the form of formal and non-formal in the midst of society. After approximately 20 years since its inception, almost every citizen is familiar with the ECD program in their neighborhood, although their level of knowledge and understanding about early childhood education institution itself is still very diverse.

In the midst of the development of early childhood education institutions are quite encouraging, there are things that are quite worrisome happened in the institution. Elderly institutions should strongly uphold the services that prioritize activities that are in line with early childhood education characteristics, as if they are losing direction by the demands of society and parents. Early childhood education educators / teachers seem to run out of mind and give up with the demands of parents / community so that their children can master reading, write, count. Fear / anxiety will lose students so that making activities in early childhood education institutions are often no less serious with activities in elementary school. Solid material, many tasks and strict rules make the main purpose of service in early childhood education institutions namely; teach children to learn to adapt, socialize and train self-reliance to be ruled out.

Services in early childhood education institutions that do not take into account the characteristics of early childhood education and learning styles of children will be fatal and disrupt the development of children in the future. In the near future it may be that the consequences for children are less visible, but in the next few years when children should be required to study seriously / earnestly to achieve their brilliant future they are already saturated for learning. Characteristics of early childhood education who like to play should be highly cared for and facilitated when they are in early childhood education institutions. Teachers should prioritize the best service for children rather than follow the wishes of parents who sometimes think less far ahead.

Playing experience is very important role for the growth and development of children. But there are still many educators and parents who have not realized it. David Whitebread, a psychologist at Cambridge University at http://www.nytimes.com/2015/05/17/opinion/sunday/let-thekids-learn-through-play.html. Say; many educators want to curtail play during school. "Play is often perceived as immature behavior that doesn't achieve anything. But it's essential to their development. They need to learn to persevere, to control attention, to control emotions. Kids learn these things through playing. [1]

Many educators want to restrict play during school. Playing is often regarded as a behavior that does not achieve anything. But play is important for their development. They need to learn to survive, to control attention, control emotions. Children learn these things through play. Based on the background that has been described then this paper aims to discuss the importance of play activities in the development and development of intelligence.

\section{CONCEPT ABOUT PLAYING FOR KIDS AGAIN}

1. Understanding of Playing.

Playing a variety of people interpreted, between one people with another sometimes have a different concept of what is meant by playing. To understand the meaning of play, the following can be put forward the opinion of some experts about play.

Hurlock in Musfiroh (2008) says play is an activity performed on the basis of a pleasure and without considering the final result. Such activities are carried out voluntarily, without coercion or pressure from outside parties[2]. But Johnson et al in Mayke (2005) says that playing is a concept that is not easy to pin down, even in the Oxford English Dictionary there are 116 definitions on playing. One example, there are experts who say play as an activity that is done repeatedly for the sake of pleasure[3]. 
Understanding the play also put forward by Santrock (2002) is a fun activity that is done for the benefit of the activity itself. According to Freud and Erikson in Santrock (2002) play / game is a form of human adjustment that is very useful to help children master anxiety and conflict. In the game the pressures are released, so the child can overcome the problems of life. The game allows the child to release excessive physical energy and liberate the hidden feelings. Meanwhile Piaget in Santrock (2002) says the game as a medium that enhances the cognitive development of children[4].

2. Stages of Play Development. In general, experts differentiate or categorize play activities without secara gamblang suggested that a type of play activities higher levels of development compared with other types of play activities. Here are some expert opinions about the development stage of play;

a) Stages of play according to Midred Parten. Midred highlights play activities as a means of socializing and he observes that there are six forms of interaction between children that occur when he plays. The stage of development play that reflects the level of social development of children is as follows;

1) Unoccupied Play. At this stage in fact the child is not really involved in the play activities, but only observe the surrounding events that attract children's attention. If nothing is interesting then they will be busy with doing things like playing their own limbs.

2) Solitary Play (play alone). At this stage the child is busy playing alone and does not seem to notice the other children around him. His egocentric behavior is indicated by the lack of effort to interact with other children. The child is just aware of the presence of others if there are other children who take the toys.

3) Onlooker Play (observer). At this stage play activities by observing other children who are doing play activities, and there seems to have been an increasing interest in the activities of other children who observed. While observing he might also ask questions and observe the behavior and conversations of the children he observes.

4) Parallel Play (playing parallel). At this stage it appears when da or more play with the same type of game equipment and perform the same movements or activities, but when noted it appears that there is actually no interaction between them. They do the same thing, individually at the same time.

5) Associative Play (associative). At this stage is marked by the interaction between children who play. The exchange of game tools, however, when observed it would seem that each child is not actually involved in cooperation.

6) Cooperative Play (playing together). At this stage is marked by the cooperation or division of tasks and the division of roles between children involved in the game to achieve a single goal.

7) Stages of playing Kathleen Stassen Berger. Kathleen distinguishes the following stages of play activities; a) Sensory motor Play (play that relies on the senses and body movements) b) Mastery Play (Play to master certain skills c) Rough and Tumble Play (rough play) d) Social Play (Play together) e) Dramatic Play (Role Playing or Fantasy)

Based on the above description can be seen that there are several stages in the development of play in children. Teachers / educators and parents of early childhood should pay attention to the stage of play in choosing and sorting games that will be given to the child.

\section{CONCEPT OF INTELLIGENCE}

\section{Understanding Intelligence}

Almost everyone has a different understanding of intelligence. It is strongly influenced by the background and point of view of the person who formulates it. According to Tony Buzan; intelligence is the ability to think in new ways to be original, and if necessary, dare to be different. Creative intelligence itself, according to him; including fluency, flexibility, authenticity and expanding ideas. While Piaget says that intelligence is what we use when we do not know what to do.

Furthermore, according to Howard Gardner, intelligence is the ability to solve or create something of value for a particular culture[5]. Intelligent people will never experience impasse in ideas or how to overcome problems, there are always thoughts or creative ideas that result. In early childhood, the indications of intelligence that has begun to be seen from the behavior it displays, therefore, various efforts can be done by parents and educators in stimulating it.

2. Types of Intelligence

Intelligence is not something that is single, but can be seen from a variety of capabilities that are controlled by someone. According to Alfred Binet and Theodore Simon; intelligence consists of three components namely; 1) the ability to direct the mind and or action, 2) the ability to change the course of action if the action has been done and, 3) the ability to self-criticize.

Meanwhile, according to Nickerson, a skill that shows his diverse intelligence; 1) the ability to classify patterns, 2) the ability to modify behavior adaptively- learn, 3) the ability to reason deductively, 4) the ability to reason inductively-to generalize, 5) the ability to develop and use conceptual models (the ability to develop and use conceptual models), and 6) the ability to understand (the ability to understand). It is known that every child has a wide range of potential intelligences. Any potential intelligence will develop well if stimulated in the right and appropriate ways. 


\section{DISCUSSION}

Naturally all children will go through periods of play. Once attached to play activities with the world of children, it is not uncommon to say that one of the characteristics of early childhood is that they love playing activities. Although many parents are also controversial with play activities, but play activities are very important for the development and development of children's intelligence potential. Many benefits can be obtained through play activities, both physical and psychological benefits.

Physically, play activities will train the child's physical skills both fine motor and rough motor child. The curiosity and pleasure that the child feels during play, will encourage the child to move around. They will crawl, walk, run, jump or even climb in exploring the environment. These conditions will directly or indirectly train the child's physical skills.

The benefits of playing for early childhood development or preschoolers have been demonstrated by Hillari L. Burdette, Robert $\mathrm{T}$ and Whitaker in his research published in the journal International "Jama Pediatrics" titled "Resurrecting free play in young children [6].

Looking beyond fitness and fatness to attention, affiliation, and affect. "From the results of research they do obtained some findings among them; 1). Early childhood is physically active in a different way than older children, adolescents, or adults). 2) Caution is a cognitive function that involves inhibition and impulse control that parents believe strongly for their ability to improve learning. 3) Problem solving that occurs when playing is believed to have a highlevel skill function that can integrate other cognitive concerns and functions such as planning, organizing, sequencing, and decision making.

From the above quotation can also be known that in addition to beneficial for the physical development of children, it turns out to play for early childhood is also useful in training concentration or attention and no less important again play can train children in solving problems. Furthermore, the increased physical skills of the child directly or not will be related to the development of knowledge and language it has. The wider room of the child will affect the more touch that will be received by the five senses, this situation will support the development of knowledge and vocabulary of children's vocabulary. Children will be more familiar with various objects, both shape, taste, color and the names of objects around it. So it can be said that the child's physical skills will support the development of mathematical intelligence and art intelligence.

The research team from Stanford University School of Medicine led by Jonathan Berger, $\mathrm{PhD}$, professor of music (https://med.stanford.edu/news/all-news/2007/07/musicmoves-brain-to-pay -attention-stanford-study-finds.html) found that "Music engages the brain over a period of time, he said, and the process of listening and play to music could be the way that the brain sharpens its ability to anticipate events and sustain attention " [7]. So playing music also has a positive impact on early childhood development, where music greatly affects the brain. Listening and playing music can be a way of sharpening the brain's ability to anticipate events and maintain attention.

\section{CONCLUSION}

Loving play activities is a characteristic of early childhood. Playing not only brings pleasure to the child, but there are many benefits children can get through playing activities. Various potential intelligence possessed by children such as physical skills, language, social, emotional, mathematics, art and so on can be stimulated through play activities. Any adult responsible for early childhood education, whether parents or educators should have a correct understanding of the importance of playing in stimulating all aspects of early childhood development.

\section{RECOMMENDATIONS}

Recognizing the importance of playing activities in the development and development of the intelligence of the early childhood, some recommendations may be put forward;

1) To parents who have the early childhood are expected to provide wider opportunities for their children to play, but still pay attention to aspects of security, comfort and educational values for children in choosing a game.

2) To educators / teachers of the early childhood should pay attention to the needs of children to play, and put forward the creativity in choosing games that will be offered to children.

\section{References}

[1] D. Kohn, "Let the kids learn through play," New York Times, 2015.

[2] T. Musfiroh, "Cerdas melalui bermain," Jakarta PT Grasindo, 2008.

[3] M. S. Tedjasaputra, Bermain, mainan dan permainan. Grasindo, 2001.

[4] J. W. Santrock, Life Span Development (Perkembangan Masa Hidup). jakarta: Erlangga, 2002.

[5] H. E. Gardner, Multiple intelligences: New horizons in theory and practice. Basic books, 2008.

[6] H. L. Burdette, T. A. Wadden, and R. C. Whitaker, "Neighborhood safety, collective efficacy, and obesity in women with young children," Obesity, vol. 14, no. 3, pp. 518-525, 2006.

[7] M. Baker, "Music moves brain to pay attention, Stanford study finds," news release, Stanford Sch. Med. http//med. stanford. edu/news_releases/2007/july/music. html, 2007. 